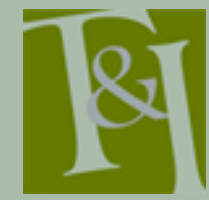

The International Journal for Translation \& Interpreting Research

trans-int.org

\title{
The TransCert Project: Ensuring That Transnational Translator Certification Meets Stakeholder Needs
}

\author{
Gerhard Budin \\ University of Vienna \\ gerhard.budin@univie.ac.at
}

Zita Krajcso

University of Vienna

zita.krajcso@univie.ac.at

Arle Lommel

GALA/DFKI

arle.lommel@gmail.com

DOI: ti.105201.2013.a08

\begin{abstract}
Certification of translators is intended to play an important role as a signal to various stakeholders (including translation companies, buyers of translation services, academic institutions, translators' association, and translators themselves) about the capabilities and training of translators. However, as not all stakeholders agree on what exactly it is that certification signals and its relevance to their requirements, current certification does not enjoy full acceptance in the marketplace. In addition, because translator certifications are currently bound to particular national geographies, they lack international acceptance. When certification does not meet stakeholder needs, they may seek alternative signaling devices from translators (e.g., custom tests, client references, or demonstrations of domain knowledge), thus limiting the value of certification in the marketplace as an economic signaling device. This article describes the EU-funded TransCert program and the results of interviews with various stakeholders concerning their issues and concerns with present and proposed certification programs. These interviews identify a number of factors and barriers that may impact acceptance of certification programs. By addressing these concerns, the TransCert hopes to overcome barriers to adoption of certification and to promote a transnational system of certification with widespread recognition.
\end{abstract}

Keywords: TransCert, translator certification

\section{Introduction ${ }^{1}$}

This article first distinguishes various types of certification and describes social and business attitudes toward the certification of translators.It then addresses how the EU-funded TransCert program can address some of the

${ }^{1}$ Acknowledgements: The authors extend their special thanks to Serge Gladkoff (GALA/Logrus) as well as the anonymous peer reviewers, for their valuable feedback. The description of the TransCert project is based on collaborative work with partners in the TransCert consortium and with advisory board members. The project TransCert has received funding from the Commissionof the European Union (LLP - EAC/27/11) under the Grant Agreement Nr. 2012-3960. 
difficulties faced by existing certification programs. Based on numerous interviews with professional translators, representatives of language service provider (LSP) companies, and institutional buyers of translation services, it presents issues that must be addressed to ensure that future certification efforts will be seen to have relevance in the marketplace. It discusses these sometimes-contradictory attitudes in the context of TransCert, which aims to design and implement a pan-European, transnational, voluntary certification program for translators. TransCert was designed with the benefits freelance translators expect from being certified, as well as the detrimental effects they fear, in mind. It also addresses the needs of a heterogeneous group of stakeholders, all of whom must "buy into" certification for it to be truly effective. In a global workforce and marketplace, certification will need to be implemented at a transnational level in order to deliver its full benefit.

\section{Framework}

Consistent with relevant international standards and the predominant usage in manyAnglophone countries, certification in this article refers to third-party attestation or validation that a product, process, or individual meets standard requirements. ${ }^{2}$ The underlying motivation for certification is to increase the quality of and/or trust in products, organizations, and persons. Certification relies on pre-determined and standardized criteria (often specified in standards documents) that are agreed upon by the stakeholders concerned.

\subsection{Types of certification}

In general there are three primary types of certification, distinguished by their object. These types apply to the translation industry as well, and any discussion of certification must keep them distinct. These types are explained below.

\subsubsection{Certification of products}

Certification of products (and services viewed as products rather than processes) focuses on qualities within the product itself, separate from the method of production or the individual producing/delivering them. This sort of certification is based on standards for product qualities. In the translation environment, product certification would be realized as a certification that a particular translated text meets certain requirements. Despite long-standing interest in this topic, there are currently no international translation standards for translation products (ISO/TC 37/SC 5 "Translation and Interpreting" is responsible for this topic).The lack of standards here is largely due to the difficulty of certifying translations themselves when faced with many varying, and potentially conflicting, usage scenarios: a translation eminently suitable for one use or scenario may not be suitable in another. However, there are projects on translation product assessment standards that could eventually become the basis of standards on how to create translation quality assessment metrics.

\footnotetext{
${ }^{2}$ In some Anglophone countries (notably Australia, New Zealand, and South Africa), this concept is referred to as accreditation. However, in international discourse and in other Anglophone countries accreditation refers to a different concept: the official recognition of a body as authorized to grant certification. (See Angelelli\&Jacobson 2009, Angelelli 2009, Russel\&Malcolm 2009, Marais 2013, Hlavac 2012, Pym et al. 2012).
} 


\subsubsection{Certification of systems}

The second type of certification focuses on managing the process used to make a product or provide a service. This manufacturing perspective assumes that by appropriately controlling the process many quality issues can be addressed. As a result relevant standards (such as the ISO $900^{3} 0$ series) focus on building relevant and repeatable processes. While the goal is to deliver a quality product, certification in this area focuses on the organizational and process structures used.

In translation, this aspect is addressed by EN $15038: 2006,{ }^{4}$ which lists process and provider requirements for quality translation. EN 15038 does not examine translated documents or certify them, although it does mandate that appropriate quality assessment procedures be in place and that translators be qualified. EN 15038 certification is currently available through the Language Industry Certification System (LICS). An international version of EN 15038 (ISO 17100) is under development.

\subsubsection{Certification of individual persons}

The third type of certification focuses on certification that individuals (subcontractors or individual service providers) have met standard requirements for knowledge, skills, and abilities or relevant experience and is the focus of this article. In this perspective, individuals must demonstrate that they are qualified to provide a particular service. For example, translators typically must demonstrate knowledge of a source and target language and working knowledge of translation skills. There are a number of translator certifications available at the national level (see the article by Jim Hlavac in this issue of Trans-Int for more details). The European Certification and Qualification Association also offers certification for different professional profiles, including terminology manager, a profession closely related to the professional profile of translators (http://www.ecqa.org/).

These three types of certification are not isolated from each other. EN 15038 , for instance, mandates that language service providers use "qualified translators" in furnishing a translation service. In addition, translators not only work for companies acting as translation service providers, but they also directly furnish translation services to clients, so they may be required to demonstrate adherence to the requirements for systems certification.

Figure 1 shows how the three types of certification are related to each other and the types of standards according to which the different objects of certification are assessed:

${ }^{3}$ The ISO 9000 family addresses various aspects of quality management and contains some of ISO's best-known standards. The standards provide guidance and tools for companies and organizations that want to ensure that their products and services consistently meet customer's requirements, and that quality is consistently improved. There are many standards in the ISO 9000 family, including:

- ISO 9001:2008 - sets out the requirements of a quality management system

- ISO 9000:2005 - covers the basic concepts and language

- ISO 9004:2009 - focuses on how to make a quality management system more efficient and effective

- ISO 19011 - sets out guidance on internal and external audits of quality management systems.

${ }^{4}$ See http://esearch.cen.eu/esearch/CatWeb.aspx $? i d=6868003$ for the national version of this standard in various European countries. 


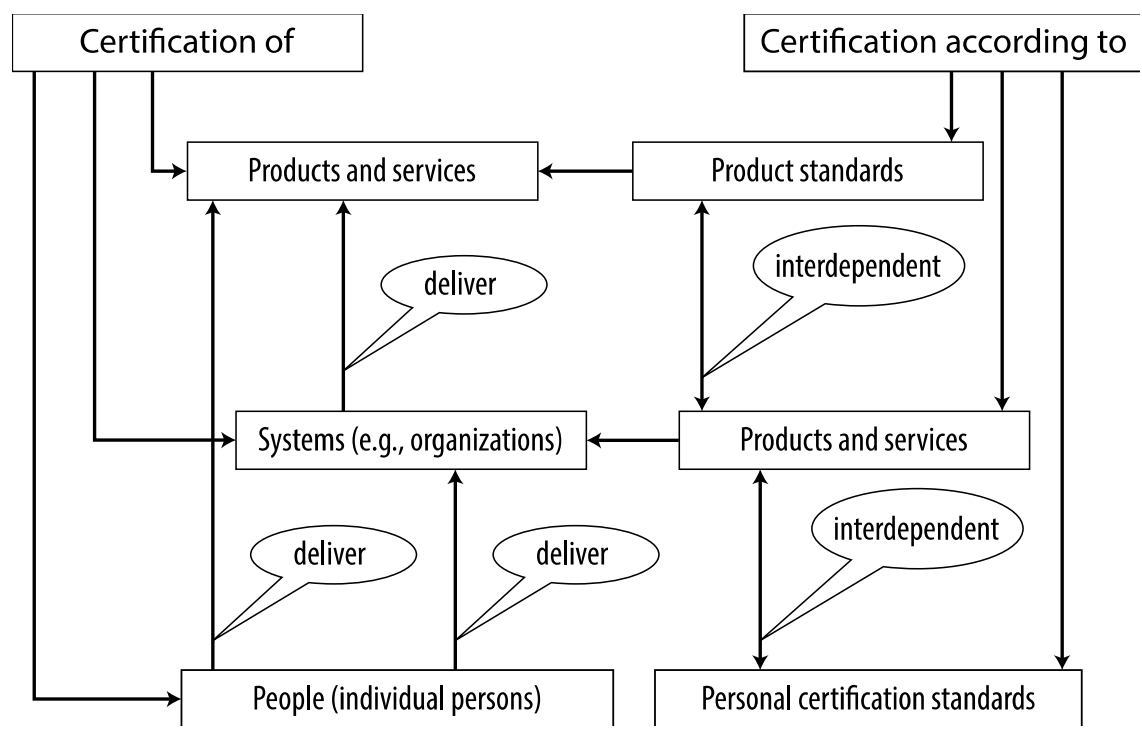

Figure 1. Types of certification and their relationship to types of standards

\subsection{Scope and Goals of the TransCert Project}

In order to address the perceived need for certification at the international level, the European Union's Directorate General Translation (DGT) set up a task force in 2011 with the mandate to discuss and determine the scope and shape of a project for the trans-European voluntary certification of translators. The task force consisted of representatives of the existing EMT (European Masters of Translation) programs, translator associations, and of translation companies (EMT 2011). As a result of the work of the task force, a consortium led by the University of Vienna submitted a project proposal called TransCert in February 2012, in response to a call for proposals by the European Union in its Lifelong Learning Programme (LLP 2012).

This study presents results of the initial work in the TransCert initiative and in a separate, but related, investigation of existing certification schemes. It focuses on specialized (technical) translators, not literary or media translators or interpreters. This focus on technical translators was discussed and decided in preliminary discussions within the TransCert task force. When the project officially begins in 2013, the question of scope will be considered for further refinement (see section 4 for more details).

The goalof offering certification to persons in the domain of translation is to provide professional translators with a transnationalproof of qualification they can present tocurrent and future employers and clients. However, if such certification is to gain widespread acceptance, it must be relevant to market needs, and cannot be seen as an "academic" or protectionist device, but must instead address needs from various stakeholder groups.

Another aim of TransCert is the professionalization of the entire translation field. Translation still has a traditional, local-oriented "cottage industry" mentality. While this paradigm has had a long history, the industry is now transforming into a technology-based, web-driven one in which economies of scale where clients outsource thousands of pages to be translated in very short time frames have become the norm. In this environment a "craft" paradigm cannot meet demands, but certification of skills relevant to modern production environments can help buyers and providers alike by allowing translation providers a way to demonstrate the relevance of their skills to today's internationally-oriented, transcultural, and networked model. 


\section{Assessing the Market Response to Current Certification}

One of the core assumptions of TransCert is that any proposed transnational certification scheme for translators must address and improve upon current national schemes. Unless a new scheme can offer a distinct change for the better, it is unlikely to succeed. Certification must also serve as an appropriate "signaling device" with real meaning to various stakeholders (see Chan 2013), or it is likely to be rejected or ignored.

In preparation for this article and submission of the proposal for the TransCert project, we interviewed (formally and informally)approximately 60 individuals active in various aspects of the translation industry concerning their perception of the value of certification and issues that impact it, with a particular goal of identifying any obstacles that impact acceptance of certification. These interviews focused on the following groups of stakeholders:

University programs in the EMT network (European Master of Translation, a quality label for translation Masters programs), as well as elsewhere.

Representatives of organizations employing or contracting with translators, primarily translation companies at the national, European (through EUATC - the European Association of Translation Companies), and international (through GALA, the Globalization and Localization Association) levels; and

Organizations representing translators at the international (FIT, International Federation of Translators) and national (through national translator associations) level.

Our interviews focused on the following general questions and topics:

Who is interested in the certification of translators?

What do translation service providers think of certification in comparison to other methods of demonstrating competence?

How important are technology skills to employers and are they covered by existing certification schemes?

Which other skills are essential to be covered by certification schemes?

Does certification increase pay rates for translators and translations?

Although the results of these interviews are qualitative rather than quantitative, certain common conclusions emerged:

Certification of translators is generally more important for language service providers (LSPs) working with governments or large corporations. In larger governmental and commercial institutions purchasing decisions are typically based on more formal criteria than in smaller companies, where personal relationships play more of a role. In particular, for government buyers, price is (in principle at least) the only consideration that can be taken into account when comparing equivalent bids. If purchase contracts require certification, substandard suppliers may be excluded from the bidding process and their lower prices cannot skew the selection process. Certification of the supply chain can help to distinguish between providers who can meet certain requirements and those that cannot. Thus certified 
translators are increasingly relevant for service providers looking for competent, reliable subcontractors with a "quality stamp" on them. (By contrast, LSPs that deal with smaller clients tend to see certification as less relevant to their clients.)

Larger LSPs are more interested in certification than smaller ones. This point relates to the previous one in that larger LSPs are also more likely to work with larger client organizations. There is a critical mass of larger LSPs with a broader service portfolio that are interested in the idea of certifying translators. In fact, for the TransCert initiative, representatives of large LSPs expressed interest in transnational certification of highly domain-specific specialized translators, e.g., medical science and technology, legal translators, or business translators.

The value of certification varies by vertical industry/domain.

Businesses active in regulated industries or industries with significant threat of litigation are more likely to require a certified supply chain. Using certified translators provides a way for them to reduce the likelihood of negative regulatory or legal outcomes. Certification therefore must be able to account for domain-specific needs and a single, one-size-fits-all general certification is unlikely to see significant uptake.

Examinations or test translations are seen as an alternative to certification, especially for LSPs working in highly specialized domains. In our interviews we repeatedly heard that ATA certification (as just one example among many) does not provide any assurance that a particular translator will be competent in a particular domain. Many LSPs therefore do not see translator certification as relevant to their work and work experience and domain expertise may be considered more reliable indicators of suitability than a (general) certification. As a result many of them either administer their own tests that focus on specific domain skills or they hire translators for a probationary period. Even if such a probationary period is not formally specified, they watch new hires closely to determine whether they will continue to work with them. Domainspecific certification could replace, in part, examinations and test translations for specific domains. However, unless certification can be shown to be at least as effective as tests in identifying resources qualified to work within specific domains, it will remain underutilized.

Current certifications schemes provide insufficient linguistic and geographic coverage. One common criticism was that any single existing certification scheme can address at best a small fraction of the market. As the number of language pairs required by business has increased and the market has shifted away from traditionally dominant languages, certification has not kept up. A number of respondents felt that it did not make sense to maintain two validation processes, one for language pairs or locales where certification is available and one for other areas. Certification programs must therefore work to expand their coverage for major markets/languagepairs.

Certification must address technology skills, not just translation skill. Many LSPs value the ability to use specific technologies more highly than certification, since their translators must work within a technology framework and training a translator to use a new set of tools takes time and money. Companies that specialize in product 
localization in particular are more likely to see general translator certification as less important because they require specialized skills not covered by certification. When asked what would be relevant to the localization industry, the response was that workflow- and technology-oriented certification schemes would be particularly interesting and translation technology competence is a major part of the competence model in the EMT that the TransCert model is based upon.

Current certification models cannot tell how well a translator will contribute to project success. One frequent criticism of current certification processes is that they focus on translation as an abstract skill, stripped from the context of how well the translator will contribute to a project's success. For example, if a certified translator produces beautiful work but cannot meet deadlines or work with others in a collaborative environment, the certification may mean little to their employer. (One response to this criticism is that a certification program could require letters of recommendation from former employers that specifically address the candidate's ability to contribute positively to project success.) Certification must therefore effectively signal to buyers that a translator will be able to meet project requirements in a professional manner.

The perceived importance of transnational certification is proportional to the geographic/linguistic scope within which a company does business. Not surprisingly, companies that work in a single market are less likely to value transnational certification since national certification meets their needs. Companies that work in multiple markets, however, place more value on a unified certification scheme since it reduces the burden to learn about and evaluate multiple schemes and helps strengthen their position and image in an international marketplace. Therefore efforts to promote transnational certification are most likely to succeed when targeting companies with a larger international profile.

None of the companies or individuals we spoke with assigned a negative value to certification and we were told that, all other things being equal, a certified translator would have an advantage in being hired, although this advantage might be slight and would not override other concerns.

When asked if certification would impact pay rates (a common argument for certification is that it would help translators make more money), we found that there was little agreement on this point. Some companies would pay more for certified translators, generally in cases where having them allowed companies to demonstrate marketplace differentiation to government or corporate buyers. On the other hand, where such a demonstration was not critical, we found that many of those we interviewed based rates on the efficiency and quality that individuals demonstrated over time, so a non-certified translator could make more than a certified translator based on project metrics and experience.Until certified translators are seen as consistently better able to contribute to project success than their noncertified counterparts, pay differential is unlikely. However, preferential hiring in which certified translators have an advantage is a more realistic short-term goal.

While these surveys summarized here did not provide quantitative data, they do suggest a number of business and social issues that the TransCert program must address if it is to meet its goals. They also suggest a number of issues that could be addressed in more systematic surveys of 
various stakeholder groups to ensure that certification schemes meet requirements. Such assessment must be ongoing to ensure that specific developments meet stakeholder requirements.

\section{The TransCert initiative and project}

Over the past threedecades the translation industry has undergone a dramatic shift in working methods and technologies. It has evolved from a loose collection of individuals interested primarily in literary works, to a multibillion euro horizontal industry essential to the success of most global industries. The language industry has shown high growth rates despite the global financial crisis and the volume of pages translated per year is sharply increasing. Despite the increased use of machine translation, more translators are working now than ever before. The number of languages into or from which service providers translate is also rising.

Increasingly translators are expected to show project management skills, problem solving strategies, and a high degree of computer literacy in order to be able to work in a hectic and competitive environment. As a consequence, the issue of innovative translator education has been addressed for many years by professionals and academics specialising in the field of translation studies.

The need to update translator-training curricula to reflect current needs resulted in the official launch in 2009 of the European Master's in Translation (EMT) under the auspices of the EC Directorate-General for Translation (DGT). EMT is a quality label for translation training programmes at the Master's level.It encourages universities across Europe to implement commonly accepted and market-oriented professional standards. Currently 53 university programs across Europe are focusing on specialized translation as part of the EMT network.

While the EMT network aims to provide innovative and high-quality translator education at a tertiary level, it is imperative to establish certification that makes sure that lifelong learning is taken seriously and that the highest standards of quality and professional relevance are maintained after translators have left these programs, as well as to provide a way for working translators to demonstrate excellence. This main objective is addressed by the TransCert project by extending the scope of recent research in translation to include vocational education and training as well asadult education. While there is currently no common EU certification for the job role of a Translator, TransCert will provide continuing professional development (CPD) and a Trans-European certification for translators.

The TransCert initiative is a long-term vision.However, the first TransCert projecthas beenfundedfor two years by the European Commission in its Life-Long Learning program, starting on January 1, 2013.The TransCert consortium consists of leading representatives of the three primary stakeholder groups in this area: university programs, translation companies, and translators associations (representing the individual translators). The consortium partners are:

- University of Vienna. The leading partner, the University of Vienna, has extensive experience as a coordinator, regional coordinator and work-package manager in national and EU-funded projects, with a strong focus on optimizing professional Information and Communications Technology (ICT)-based translator training and translation standardization. 
- ISIT Paris. The ISIT in Paris is another of the leading universities in Europe offering high-quality translation training with a strong focus on domain specific translation and qualifying translators for international organizations (EU, UN).

- Lessius Antwerpen. Lessiushas extensive experience in developing and revising certified courses and in drafting ICT-based course materials, in standardization (ISO TC 37) and certification (ECQA, Federal Public Services in Belgium, LICS Auditor, EMT competence profiles).

- International Software Consulting Network (ISCN). ISCN, the technological provider for the ECQA, supports the development of skills cards, online skills assessment and the integration of new job roles (professions) to the ECQA Framework, and manages the technology configurations of the LMS system. It closely works with TermNet that is leading the closely related professional profile of terminology manager.

- INTERTEXT. INTERTEXT is an agency for translation and interpreting services and represents the synergy between translators and customers in this project.

- European Union Association of Translation Companies (EUATC). EUATC provides a united voice for translation companies to promote the highest standards in quality business practice and training of translators, thus solving common issues affecting the translation industry across Europe.

- Globalization and Localization Association (GALA). GALA is the largest non-profit global organization within the localization industry providing resources, education, ideas, and research to enhance the performance of the translation sector.

In addition, TransCert has an Advisory Board responsible for the scientific assessment of project activities. The advisory board members give feedback on public and internal drafts, providing a second level of quality assurance.All Advisory Board members are experts with a strong international reputation in the area of translator training and certification. Within the Advisory Board, TISAC, ATA and NAATI represent the global perspective of the project, and will work together with TransCert to create an accreditation body for certification programs in order to establish standards of professional practice.

The involvement of all stakeholders in the field will help ensure the quality and sustainability of transnational voluntary certification for translators, and will be open to non-European and non-EU countries all over the world. The various organizations and bodies involved with TransCert will consider feedback on current certification provided in this article to help ensure that the results will be seen as relevant and useful across the various stakeholder segments. We believe that the structure of this initial project and its focus on real-world project-oriented skills will help overcome the limitations of previous certification efforts noted in section 3 of this article.

\subsection{Aims and objectives of the TransCert project}

The aim of the TransCert project is to develop a complete certification and training program (with a certificate, training scheme, training materials, eLearning portal etc.) for individuals working in positions under the job profile of "translator." TransCert will offer: 
A joint, common certification framework agreed upon among all stakeholders

A certification portal

A "skillcard" for the job profile of translator

ICT-based training materials

An examination scheme based on the above skill card.

While we anticipate that translator-training programs will want to ensure that their students will be prepared for the TransCert examination, it is important to note that the training developed by the TransCert project is not intended to replacecurrent translator-training programmesand/or substantial real-life experience. Rather, TransCert will help candidates prepare for the certification exam once the necessary skills have been acquired over a period of years.

The ICT-based training scheme will be closely linked to networked learning environments where translators can acquire relevant skills (e.g., in university-based Master's courses using the EMT standards as best practice) and industry-based training schemes, as well as training offered by professional associations.

The innovative approach of the TransCert certification scheme combines best practices in translation quality assurance (e.g. EN 15038), industry certification at the European level (e.g. ECQA), and international standards in personal certification (e.g. ISO $17024-$ General requirements for bodies operating certification of persons).

The TransCert training program will also ensure that the continual education of employees will be fostered. On a broader scale, the skillset will raise awareness with regard to the value and importance of languages, helping to enhance Europe's linguistic diversity. Certification will establish standards of professional practice and thus ensure professional competence and competitiveness. The project will use available mechanisms (e.g., ECQA) and best practices to introduce TransCert certification. The labor market is international and available for participants irrespective of gender or nationality. However, as the translation profession has a majority of women, we anticipate that the project will contribute to the improvement of the position and status of women. Increasing transparency and recognition of their qualifications will lead to better employability and equality in the labor market.

Based on our interaction with various stakeholder groups, we also see the following factors as critical for success:

1. Certification will need to be flexible over timeso that it can react to market trends. It must adapt to various situations.

2. Specialized types of certification programs (e.g., for different domains or task types) will need to be developed within the TransCert framework in addition to general certification. The flexibility of a core certification with optional modules will enable translators to tailor their certifications to their strengths and target customer base.

3. The right skill set focusing on a high degree of IT literacy, project management skills, and personal social competences (such as working under stress, and working in collaborative distributed teams in complex workflows) will be imperative. Demonstration of projectoriented skills might be achieved through letters of recommendation for working translators, but certification should also focus on demonstration of relevant knowledge. 


\section{Conclusions}

Based on our examination of existing certification schemes and our discussion with various stakeholder groups, we believe that TransCert certification can fill a need in industry today. Currently companies have difficulty finding and validating skilled human resources (translators). Because of the geographic and/or linguistic limitations of current schemes, none of them can address more than a small fraction of the market, leaving many qualified professionals unable to take advantage of certification. In addition, if TransCert can demonstrate the relevance of its standards to project success (rather than just to skill as a translator) and also allow for the development of domain- and task-specific modules, we believe that it can overcome many of the limitations seen in current certification.

It has become clear that different target audiences and stakeholder communities have different expectations. While university representatives, in particular from the EMT programs, are concerned that the value of the EMT graduation should not be undermined by certification systems, translation companies are either skeptical about certification systems that are not controlled by themselves or they are positive about the need for certified translators on the market as a signal of quality. The third stakeholder community is comprised of translators themselves, usually represented by national as well as international (FIT-member) translator associations. Translators are often skeptical of certification schemes that do not relate to their working conditions or that impose seemingly arbitrary results. Until translators see a financial motivation (i.e., they receive jobs because they are certified or they can command a higher price because they are certified), the appeal of certification may remain limited.

In order to convince skeptics in the academic community (particularlythose from EMT programs) that TransCert certification will be beneficial to their graduates, we propose to offer graduates from EMT or other quality-labeledprograms "junior status," and the promise that after demonstrating two years of professional expertise (as documented on their personal ePortfolio) they would qualify for full status.

To ensure that certification remains valid as customer requirements change, periodic re-certification would be necessary.Thus TransCert certification would have time-limited validity, similar to the way that driver's licenses that have to be renewed in some countries.

If the process of European integration continuesas expected in coming years, and the global scope of both the translation industry's customer base and service offeringscontinues todevelop, the task of finding and identifying quality translators across increasing numbers of language pairs and subject domains will only become more difficult. We therefore anticipate that stakeholders will increasingly welcome and accept a transnational, international certification system that is trusted and sustainable.Current efforts in developing standards for the translation industry in ISO TC 37 Sub-committee 5 (Translation and Interpreting) may also be an important building block in providing quality standards for all three types of certification objects. Within this context, we believe that the 
need for ways to "signal" quality to the market ${ }^{5}$ will only increase. As the limits of current nation-based certification have become increasingly apparent within the market, we maintain that a transnational program, like TransCert, will be needed to solve this issue.

${ }^{5}$ See Pym, Grin, Sfreddo, \&Chan (2012) and Andy Chan's contribution to this issue for a detailed overview of how quality is currently "signaled" on the market. 


\section{References}

Angelelli, C. V. (2009). Using a rubric to assess translation ability: Defining the construct. In C. V. Angelelli \&H. E. Jacobson (Eds.),Testing and assessment in translation and interpreting studies (pp. 13-48). Amsterdam: John Benjamins.

Angelelli, C. V. \& Jacobson, H. E. (Eds.).(2009). Testing and assessment in translation and interpreting studies. Amsterdam: John Benjamins.

American Translators Association (ATA).(n.d.)ATA certification program. Retrieved December 21, 2012, from http://www.atanet.org/certification/.

Chan, A. L. J. (in press). Signal jamming in the translation market and the complementary roles of certification and diplomas in developing multilateral signaling mechanisms. Translation \&Interpreting,4(2).

ECQA. (n.d.).European Certification and Qualification Association. Retrieved December 21, 2012, fromhttp://ecqa.org/.

EMT. (2011). EMT Annual Report 2011.Retrieved December 21, 2012, from http://ec.europa.eu/dgs/translation/programmes/emt/key_documents/e mt_annual_report2011_en.pdf.

Hlavac, J. (in press).A cross-national overview of translator and interpreter certification procedures.Translation \&Interpreting,4(2).

Lifelong Learning Programme (LLP).(2012). LLP call for proposals 2012. Call EAC/27/11 (2011/C 233/06). Call for proposals: Multilateral projects, networks, accompanying measures under the subprogrammes, transversal programme (key activities). Retrieved December 15, 2012, from http://eacea.ec.europa.eu/llp/funding/2012/call_lifelong_learning_20 12.php.

Marais, K. (in press). Constructive alignment in translator education: Reconsidering assessment for both industry and academy. Translation \&Interpreting, 4(2).

Pym, A., Grin, F., Sfreddo, C., \& Chan, A. L. J. (2012).Thestatus of the translation profession in the European Union(final report July, 24 2012). Luxembourg: Publications Office of the European Union.

Russell, D.,\& Malcolm, K. (2009). Assessing ASL-English interpreters: The Canadian model of national certification. In C. V. Angelelli \&H. E. Jacobson (Eds.),Testing and assessment in translation and interpreting studies (pp. 331-76). Amsterdam: John Benjamins. 